Rovira, E., Cuadras, A., Aguilar, X., Esteban, L., Borras-Santos, A., Zock, J.P., Sunyer, J. Asthma, respiratory symptoms and lung function in children living near a petrochemical site.

\begin{tabular}{|l|l|}
\hline $\begin{array}{l}\text { Postprint } \\
\text { Version }\end{array}$ & 1.0 \\
\hline Journal website & http://www.sciencedirect.com/science/article/pii/S0013935114001832 \\
\hline Pubmed link & http://www.ncbi.nlm.nih.gov/pubmed/24949814 \\
\hline DOI & $10.1016 /$ j.envres.2014.05.022
\end{tabular}

This is a NIVEL certified Post Print, more info at http://www.nivel.eu

\title{
Asthma, respiratory symptoms and lung function in children living near a petrochemical site $\hat{\imath}$
}

\author{
ENRIC ROVIRA ${ }^{\mathrm{A}, \mathrm{B},}$ ANNA CUADRAS ${ }^{\mathrm{A}, \mathrm{B},}$ XAVIER AGUILAR ${ }^{\mathrm{C},}$ LEONARDO ESTEBAN $^{\mathrm{C},}$ ALÍCIA \\ BORRÀS-SANTOS ${ }^{\mathrm{D}, \mathrm{E}, \mathrm{F},}$ JAN-PAUL ZOCK ${ }^{\mathrm{D}, \mathrm{E}, \mathrm{F}, \mathrm{G},}$ JORDI SUNYER ${ }^{\mathrm{D}, \mathrm{E}, \mathrm{F}, \mathrm{H},}$ \\ ${ }^{a}$ Observatory of Health and Environment, Catalonia Public Health Agency, Health \\ Department, Generalitat de Catalunya, Av. Maria Cristina, 54, Tarragona 43002, Spain \\ ${ }^{b}$ Institut d'Investigació Sanitària Pere Virgili, Av. de la Universitat, 1, Reus 43204, Spain \\ ${ }^{c}$ Pneumology Service, Tarragona University Hospital Joan XXIII, Institut Català de la Salut, \\ c/Doctor Mallafré Guasch, 4, Tarragona 43005, Spain \\ ${ }^{d}$ Centre for Research in Environmental Epidemiology (CREAL), c/Doctor Aiguader, 88, \\ Barcelona 08003, Spain \\ e Universitat Pompeu Fabra (UPF), Plaça de la Mercè, 10-12, Barcelona 08002, Spain \\ ${ }^{\dagger}$ CIBER Epidemiología y Salud Pública (CIBERESP), Spain \\ ${ }^{9}$ Netherlands Institute for Health Services Research (NIVEL), P.O. Box 1568, Utrecht 3500 \\ $\mathrm{BN}$, the Netherlands \\ h IMIM (Hospital del Mar Medical Research Institute), Passeig Marítim, 25-29, Barcelona \\ 08003, Spain
}

\begin{abstract}
Residential proximity to environmental hazards has been related to adverse health outcomes. Respiratory health and allergies in children living near petrochemical sites have not been extensively studied. We evaluated the association between residential proximity to the petrochemical site of Tarragona (Catalonia, Spain) and the prevalence of asthma, respiratory symptoms and lung function in children. Children aged 6-7 $(n=2672)$ and adolescents aged 13-14 $(n=2524)$ residing near two large petrochemical sites and those living in a city with medium vehicular traffic were cross-sectionally compared with children from an area with low vehicular traffic and without industry. The prevalence of symptoms was measured using the International Study of Asthma and Allergies in Childhood written and video questionnaires. Lung function measurements were done in a subsample of 959 adolescents in the four areas. Multivariable analyses were done to estimate the effects of the residential area on symptoms and lung function adjusted for potential confounders. Crude prevalence of symptoms was similar across the studied areas. After adjustment, children and adolescents living near a petrochemical site had a statistically significant higher
\end{abstract}


Rovira, E., Cuadras, A., Aguilar, X., Esteban, L., Borras-Santos, A., Zock, J.P., Sunyer, J. Asthma, respiratory symptoms and lung function in children living near a petrochemical site. Environmental Research: 2014, 133, 156-163

prevalence of respiratory hospitalizations in the previous year (Prevalence Ratio $(\mathrm{PR})=1.49$; 95\%CI, 1.06-2.09) and of nocturnal cough (PR=1.29; 95\%CI 1.051.57), respectively. Reduced lung function values among adolescents residing near the petrochemical areas were not observed. Although a higher prevalence of asthma in children and adolescents living near the petrochemical sites could not be demonstrated, as described in other studies, respiratory hospitalizations and nocturnal cough could be related to short-term exposures to pollutants. Other clinical and sub-clinical respiratory health effects in the petrochemical industry areas should be investigated.

\author{
ABBreviations \\ $\mathrm{SO}_{2}$, Sulfur dioxide; \\ $\mathrm{NO}_{2}$, Nitrogen dioxide; \\ $\mathrm{PM}_{10}$, Particulate matter with an aerodynamic diameter less than $10 \mu \mathrm{m}$; \\ $\mathrm{PM}_{2.5}$, Particulate matter with an aerodynamic diameter less than $2.5 \mu \mathrm{m}$; \\ PAH, Polycyclic aromatic hydrocarbons; \\ FAS, Family Affluence Scale; \\ FVC, Forced vital capacity; \\ $\mathrm{FEV}_{1}$, Forced expiratory volume within 1 second; \\ PEF, Peak expiratory flow; \\ ISAAC, International Study of Asthma and Allergies in Childhood
}

\title{
1. INTRODUCTION
}

Asthma, allergic rhinitis and eczema in childhood are important public health concerns, not only in terms of health care costs but also in terms of school absenteeism and quality of life (Braman, 2006). The available data suggest that in high-income countries, asthma prevalence is continuing to increase or has reached a plateau (Anandan et al., 2010). Children's lungs are more susceptible to airborne environmental exposures and there is strong support for air pollution effects on the development of lung function in children and adolescents (Götschi et al., 2008, Miller and Marty, 2010 and Duijts, 2012). It is well know that ambient air pollution is a possible cause of variations in asthma prevalence through effects on incidence, severity, prognosis and duration (Bateson and Schwartz, 2008, Holguin, 2008 and Tzivian, 2011).

Oil refineries and petrochemical plants release a wide range of volatile agents and particulate matter into the atmosphere. Residential proximity to these industrial sites has been linked with cancer, adverse pregnancy outcomes and respiratory disorders (Yang et al., 2004, Whitworth et al., 2008 and Brender et al., 2011). The association between asthma symptoms in children and proximity to petrochemical sites has been demonstrated in several studies (Ware et al., 1993, Yang et al., 1998, Loyo-Berríos et al., 2007, Smargiassi et al., 2009, White et al., 2009, Wichmann et al., 2009, Moraes et al., 2010 and Rusconi et al., 2011).

The largest chemical site in southern Europe and the Mediterranean region is located in Tarragona county (Catalonia, north-eastern Spain). In local communities there is growing concern about the possible link between living close to the site and respiratory disorders, particularly asthma. Since the petrochemical activity started in the 1960s, the impact of air pollution on respiratory health of children has not been 
Rovira, E., Cuadras, A., Aguilar, X., Esteban, L., Borras-Santos, A., Zock, J.P., Sunyer, J. Asthma, respiratory symptoms and lung function in children living near a petrochemical site. Environmental Research: 2014, 133, 156-163

studied. Evaluating the impact of industry may contribute to policies aiming at a decrease of health effects in children.

The aims of this study were to estimate the prevalence and severity of asthma as well as respiratory and allergic symptoms and to evaluate lung function of children living near the petrochemical sites of Tarragona and children living in areas with urban pollution compared with children living in relatively unpolluted areas of the county. We hypothesized that exposure to petrochemical pollutants would lead to consequences on the respiratory health of children living near the industrial areas.

\section{MATERIAL AND METHODS}

\subsection{Study area}

Tarragona city (140,184 inhabitants, 2010) is the main town of the county (249,718 inhabitants, 2010). Furthermore, an important seasonal increase of population related to tourism takes place in summer. The chemical site of Tarragona is divided into two main areas: First, the North Industrial Complex $\left(4.7 \mathrm{~km}^{2}\right)$ is located $10 \mathrm{~km}$ north of the main city and includes an oil refinery and other chemical industries. Second, the South Industrial Complex $\left(7.2 \mathrm{~km}^{2}\right)$, is located parallel to the coast and contains several chemical and petrochemical plants. Many residential neighborhoods are located close to the industrial facilities (Fig. 1).

\section{[FIGURE 1]}

Among the products manufactured by companies established in the North Industrial Complex are benzene, ethylene, fuel oil, gasoline, kerosene, propylene, propylene oxide, polypropylene and styrene. Companies established in the South Industrial Complex produce diverse compounds such as acrylonitrile-butadiene-styrene (ABS), butane, chlorine, ethylene oxide, polyethylene, kerosene, halogenated organic compounds, polyols, polypropylene, polystyrene, polyethylene, polyvinyl chloride, propane and vinyl acetate. The total production of the two complexes is about 19 million tons per year (14 million tons in the North Industrial Complex and 5 million tons in the South Industrial Complex (AEQT, 2010)).

Atmospheric emissions of sulfur oxides, nitrogen oxides and non-methane organic volatile compounds have been estimated at 14,209, 8982 and 3064 t per year, respectively (PRTR-España, 2010).

Other industrial point sources of air pollution in this area include a municipal solid waste incinerator and a hazardous waste incinerator (168,000 and 45,000 t processed per year, respectively) and two power plants using natural gas (production capacity of about $800 \mathrm{MW}$ ). Mobile sources include motor vehicle emissions from a motorway (32,000 vehicles per day) and two highways (one parallel to the coast, 20,000 vehicles per day, $6 \%$ heavy duty; other to Tarragona from the North, 16,000 vehicles per day, 6\% heavy duty (Ministerio de Fomento, 2010)). 54\% of the county vehicles are registered in Tarragona city (private car, 62,558 and lorry and van, 11,608 (Institut d'Estadística de Catalunya, 2010)). In addition, a harbor in the zone handles crude oil and chemical products as well as coal, other minerals and cereals. The amount of soybean hulls unloaded in the harbor is significantly lower than in the past (Rovira et al., 2010).

The area has a Mediterranean climate characterized by warm summers, moderate winters and irregular and scarce rainfall: (average temperature, $14.9^{\circ} \mathrm{C}(7.5-24.9)$; 
Rovira, E., Cuadras, A., Aguilar, X., Esteban, L., Borras-Santos, A., Zock, J.P., Sunyer, J. Asthma, respiratory symptoms and lung function in children living near a petrochemical site. Environmental Research: 2014, 133, 156-163

precipitation accumulated, $414 \mathrm{~mm}$; relative humidity, 68\% (63-71); maximum solar radiation, $15.7 \mathrm{MJ} / \mathrm{m}^{2}$, in a meteorological station closest to the refinery).

Predominant winds are from the south in summer and from the north during the rest of the year. Inversion conditions are uncommon (Generalitat de Catalunya. Servei Meteorològic de Catalunya, 2010).

According to the local air quality monitoring network, the ranges of $\mathrm{SO}_{2}, \mathrm{NO}_{2}, \mathrm{PM}_{10}$, $\mathrm{PM}_{2.5}$, benzene and benzo(a)pyrene annual average for 2010, were $2-6 \mu \mathrm{g} / \mathrm{m}^{3}, 15-29$ $\mu \mathrm{g} / \mathrm{m}^{3}, 17-30 \mu \mathrm{g} / \mathrm{m}^{3}, 10-11 \mu \mathrm{g} / \mathrm{m}^{3}, 0.9-3.7 \mu \mathrm{g} / \mathrm{m}^{3}$ and $0.11 \mathrm{ng} / \mathrm{m}^{3}$, respectively (Generalitat de Catalunya. Departament de Territori i Sostenibilitat, 2010). Ozone episodes (hourly averages of more than $180 \mu \mathrm{g} / \mathrm{m}^{3}$ ) are not rare in summer. Levels of polycyclic aromatic hydrocarbons (PAH) in soils and vegetation of Tarragona County are periodically monitored and are similar to those registered in other urban and industrial zones of Europe (Nadal et al., 2011). The total average $\mathrm{PAH}$ levels in the air near the petrochemical site are comparable with those measured in industrial sites and in suburban areas in Europe (Ramírez et al., 2011).

Considering environmental and dietary intake, the concentrations of PAH in Tarragona County do not involve a significant additional non-carcinogenic and carcinogenic risk (Linares et al., 2010). Risk assessment related to atmospheric volatile organic compounds evaluated in previous studies have shown average concentrations below their chronic reference concentrations for non-carcinogenic effects (Ramírez et al., 2012).

We divided the municipalities into four areas according to their proximity to industry (Fig. 1): North Industrial Complex (NC), South Industrial Complex (SC), Tarragona city center (TC), the urban area with medium vehicular traffic and the rest of the county (RC) with low vehicular traffic and no industry.

\subsection{Study participants}

Schools were used as sampling units. The target age ranges were 6-7 and 13-14. First grade primary and second grade secondary school students were selected for the study. The entire list of the schools from the four areas was selected: 67 primary schools (2672 children aged 6-7 years) and 32 secondary schools (2524 adolescents aged 13-14 years). Children placed in special instructional units were excluded. The study population consisted of school children who both lived and attended schools in one of the four study areas.

The governing bodies of all schools in the area gave their consent and cooperation for the study, as the educational authorities. Parents of potential participants were sent a letter explaining the nature of the study and asking written informed consent for their children to participate in the study. The study protocol was approved by the Ethics Committee of Tarragona University Hospital Joan XXIII.

\subsection{Questionnaires}

Health information was obtained using the core questionnaire on asthma, rhinitis and eczema from the International Study on Asthma and Allergies in Children (ISAAC) (Asher et al., 2006 and International Study of Asthma and Allergies in Childhood Phase Three Study Group, 2009). Questionnaires were available in two local languages, Catalan and Spanish that had been translated following the ISAAC protocol.

School teachers distributed the questionnaires to the children and they also collected them after they had been completed by the parents at home. A self-administered 
Rovira, E., Cuadras, A., Aguilar, X., Esteban, L., Borras-Santos, A., Zock, J.P., Sunyer, J. Asthma, respiratory symptoms and lung function in children living near a petrochemical site. Environmental Research: 2014, 133, 156-163

questionnaire was completed in the school setting by adolescents. The ISAAC international video asthma questionnaire with verbal instructions in Spanish was shown to the adolescents after they had completed the written questionnaire. Data were collected between March and June 2010.

In addition to the ISAAC questionnaire, demographic and environmental data were collected. Demographic information included date of birth, gender, place of birth, parental nationality (foreign nationality was defined as both parents born abroad), length of residence in the town and parental educational level (highest of mother and father). Socioeconomic family level was measured using the Family Affluence Scale test (FAS) (Currie et al., 2008), a validated indicator that includes information about family car ownership, bedroom occupancy, family holidays in the past year and computer ownership. The summed scores produce an ordinal scale in three affluence levels: low, intermediate and high. Additional questionnaire items included family history of asthma (at least one parent with history of asthma), length of breastfeeding, respiratory hospitalizations in the last year (only for children), potential indoor exposures as type of cooking, presence of pets in the house and exposure to environmental tobacco smoke at home (at least one person currently smoking in the house). Adolescent smoking habits were also recorded; those who smoked regularly, even "less frequently that once a week", were defined as smokers. The definition of respiratory health outcomes were those of the ISAAC questionnaire (Lai et al., 2009). Asthma prevalence was determined by past and current (preceding 12 months) wheezing episodes, persistent cough unrelated to colds and influenza and ever having had a lifetime history of asthma. The severity of current wheezing was defined as an affirmative response to at least one of the following questions: frequency of wheezing attacks (four or more), episodes that disturbed sleep (one or more nights per week) and episodes that limited speech (at least one). Questions related to the prevalence of allergic rhinitis were past or current rhinitis (preceding 12 months) and itchy/watery eyes in the previous year unrelated to colds or influenza. Atopic eczema prevalence was determined by past or current (preceding 12 months) chronic itchy rash. The definition of wheeze by video questionnaire was a positive response to the first scene (wheezing at rest in the last 12 months).

\subsection{Lung function testing}

A sub-sample of secondary schools ( 9 centers, 959 adolescents) in each area ( $\mathrm{NC}=2$, $\mathrm{SC}=3, \mathrm{TC}=3$ and $\mathrm{RC}=1$ ) were selected to measure lung function by means of forced spirometry testing. A trained nurse performed the pulmonary function tests in all selected schools using a portable spirometer (EasyOne, NDD Medical Technologies, Zürich, Switzerland) with computerized data acquisition software in a portable computer. The same technician carried out the spirometry tests in all schools after regular calibration. Lung function was measured according to American Thoracic Society and European Respiratory Society guidelines (Miller et al., 2005).

Spirometry was performed at school during morning hours ( $8.30 \mathrm{am}-2 \mathrm{pm})$ between March and June 2010. Standing height and weight were measured using standardized equipments and procedures in all schools.

Spirograms were validated by two independent observers to meet the betweenmaneuver acceptability criteria (Miller et al., 2005). The following variables were obtained from the best of 3 reproducible forced expiratory maneuvers: (1) forced vital capacity (FVC, l), (2) forced expiratory volume in the first second $\left(\mathrm{FEV}_{1}, \mathrm{l}\right),(3)$ peak expiratory flow rate (PEF, l/s) and (4) forced expiratory flow between $25 \%$ and 
Rovira, E., Cuadras, A., Aguilar, X., Esteban, L., Borras-Santos, A., Zock, J.P., Sunyer, J. Asthma, respiratory symptoms and lung function in children living near a petrochemical site. Environmental Research: 2014, 133, 156-163

75\% expired volumes $\left(\mathrm{FEF}_{25-75}, \mathrm{l} / \mathrm{s}\right)$. The best $\mathrm{FVC}$ and $\mathrm{FEV}_{1}$ were recorded, whereas $\mathrm{FEF}_{25-75}$ were derived from the best curve, defined as the greatest sum of FVC and $\mathrm{FEV}_{1}$ (Miller et al., 2005). We calculated the ratio (FEV $/ \mathrm{FVC}$, \%) and the percent of predicted values on the basis of reference equations for the Spanish population based on gender, age, height and weight (Casan, 1985).

\subsection{Statistical analysis}

A cross-sectional study was conducted. All analyses were carried out separately by age group. First, a descriptive analysis was carried out by calculating the symptom prevalence. Differences between geographical areas and control area were assessed using chi-square tests. Differences in asthma and allergy symptoms between the industrial and urban areas and the control area were analyzed by using the Poisson log-linear regression analyses adjusting for potential confounding variables (gender, length of residence in the town, parents nationality, parental history of asthma, family affluence and passive and active smoking). Results are presented as prevalence ratios (PR) with 95\% confidence intervals (CI). Differences in lung function indices were analyzed using multivariable linear regression adjusting for identical confounding variables plus weight, height and height squared. A $p$ value less than 0.05 was considered to be statistically significant. Statistical analyses were performed with SPSS 18.0 (SPSS Inc., Chicago, IL, USA).

\section{RESULTS}

All 99 schools agreed to participating in the study. Completed questionnaires were obtained for 1575 children (response rate 59\%) and 1947 adolescents (response rate $77 \%$ ). Compliance was higher in the schools of TC and was similar in the other areas. After excluding questionnaires with incomplete or invalid addresses, with missing information on health questions, for children outside the target age range or with residence outside the study area, a total of 1511 children and 1594 adolescents were included in the analysis. 1874 adolescents completed the video questionnaire (response rate 74\%) and after exclusions the final number for analysis was 1544 . There were significant differences in the demographic characteristics of children and adolescents from the different study areas (Table 1). Children and adolescents living in TC had been living for a longer period in the town, those living in the SC had more often a foreign family origin and those living in NC and SC were of lower socioeconomic and educational family status. Children in NC had been more frequently sent to hospital for respiratory disease in the last year. The prevalence of adolescent tobacco consumption was higher in RC.

\section{[TABLE 1]}

In the young age group, the reported prevalence of current wheeze, ever wheeze and ever asthma was relatively similar across the four areas (Table 2). Severity of wheeze was higher in NC, SC and TC, but not statistically significantly so. The prevalence of children with atopic dermatitis was significantly lower in SC.

\section{[TABLE 2]}

In the adolescent group, the reported one-year period prevalence of wheezing and wheeze ever was significantly lower in TC (Table 2). The prevalence of nocturnal cough was significantly higher in the NC. The prevalence of current and ever 
Rovira, E., Cuadras, A., Aguilar, X., Esteban, L., Borras-Santos, A., Zock, J.P., Sunyer, J. Asthma, respiratory symptoms and lung function in children living near a petrochemical site. Environmental Research: 2014, 133, 156-163

wheezing obtained by the video questionnaire was generally lower and followed identical patterns as that obtained from the written questionnaire (see Table 1 in the Supplementary data).

There was a substantial variation in the prevalence of certain symptoms between the two age groups, especially for wheezing after exercise, current wheezing, asthma ever, rhinitis, rhinoconjunctivitis and severe wheezing.

After adjusting for the potentially confounding factors, children living in the industrial and urban areas did not have higher prevalences of symptoms than children living in the control area (Fig. 2 and see Fig. 1 in the Supplementary data). The prevalence ratio of hospitalizations for respiratory disease in children was significantly higher in NC (PR=1.49; 95\%CI, 1.06-2.09). In adolescents, the prevalence of nocturnal cough in the last year (PR=1.29; 95\%CI, 1.05-1.57) was significantly higher in NC, and wheezing ever ( $P R=0.75$; 95\%CI, 0.59-0.96) and wheezing in the last year ( $\mathrm{PR}=0.69 ; 95 \% \mathrm{CI}, 0.49-0.98)$ were significantly lower in TC.

\section{[FIGURE 2]}

We were able to perform 764 lung function tests (response rate 80\%). After the quality revision and excluding tests without a written questionnaire, tests of children outside the target age range and children with residence outside the study area, 525 valid tests (69\%) were included in the analysis. Anthropometric measures and lung function parameters are shown in Table 3 (see values by sex in Table 2 in the Supplementary data). Compared to the control area, no consistent trend of reduced pulmonary function parameters was observed among the adolescents living in the industrial and the urban area (Table 3). In the multivariable analysis, adjusting for potential confounders, no differences were found in the lung function values between subjects living in the different areas (Table 4).

\section{[TABLE 3]}

\section{[TABLE 4]}

\section{Discussion}

In contrast to previous studies performed in large populations of children using the ISAAC questionnaire and other similar protocols (Ware et al., 1993, Yang et al., 1998, Loyo-Berríos et al., 2007, White et al., 2009, Wichmann et al., 2009, Moraes et al., 2010 and Rusconi et al., 2011), we did not find higher prevalences of asthma and allergic symptoms in children and adolescents living near a petrochemical site compared to those living in the control area. Moreover, in contrast with the only two studies performing spirometry (Wichmann et al., 2009 and Rusconi et al., 2011) we did not find a lower lung function.

Differences in respiratory health effects between studies may be related to qualitative and quantitative differences in exposure characteristics of petrochemical sites. A site can have significantly different air emission point amounts depending on the location (predominant wind direction and speed, humidity, sun radiation and precipitation), the industrial procedures (crude oil quality, industry age, compounds produced, production technology and pollution control equipment), other industrial activities 
Rovira, E., Cuadras, A., Aguilar, X., Esteban, L., Borras-Santos, A., Zock, J.P., Sunyer, J. Asthma, respiratory symptoms and lung function in children living near a petrochemical site. Environmental Research: 2014, 133, 156-163

(other pollutant industries, waste incinerators, power plants and harbors in the area) other sources of pollution (traffic and construction) and the air quality monitoring and regulation. Moreover, the characteristics of the susceptible population (age distribution, migration status, socioeconomic level, diet or active and passive exposure to tobacco smoke) and the urban residence (downwind/upwind, distance to point-source, distance to busy roads, resources like parks or green areas) can differ. Exposure patterns can also probably change over time.

The significantly higher prevalence of respiratory hospitalizations and nocturnal cough in the petroleum refinery area observed in the present study, probably represents the effects of short-term exposures to a pollutant mixture. An association between daily sulfur dioxide peak levels and asthma hospitalizations was observed among children 2-4 years of age living in close proximity to petroleum refineries in Montreal (Smargiassi et al., 2009). Other stack and/or fugitive refinery emissions such as $\mathrm{PM}_{2.5}$ and volatile organic compounds could also be involved. Petrochemical industry air emissions include volatile organic compounds and combustion products such oxides of nitrogen, sulfur dioxide, hydrogen sulfide, carbon monoxide, carbon dioxide and particulate matter. Volatile organic compounds originate from pipingsystem fugitive leaks, product loading, atmospheric storage tanks and wastewater collection and treatment and the second group of products come from combustion of fuels in boilers, furnaces, heaters gas turbines, generators and the catalytic cracker (IPIECA, 2012). The different impact between the two industrial sites could be explained by the higher amount of refinery emissions in the North Industrial Complex.

The influence of socioeconomic factors on exposure and susceptibility of children to environmental factors has been widely recognized (Hoffmann et al., 2009, Bolte et al., 2010, Hafkamp-de Groen et al., 2012, Bell and Ebisu, 2012 and Moore et al., 2012). Industrial neighborhoods are generally less desirable for residential purposes, except for the less educated and/or the economically disadvantaged. The educational level of parents is important for understanding the questions and may condition the answers and symptoms identification. The prevalence of smoking parents in our study and the children's second-hand smoke exposure is higher among lower socioeconomic status. Geographical differences in health care access or in asthma management among physicians can influence asthma diagnosis. Since the populations in our study differed significantly in terms of socioeconomic status, the indicator FAS has been used to control for possible socioeconomic confounders. FAS has provided an elevated number of responses and has solved the problem of the high number of incorrect and missing responses when parent educational level or occupational status is reported directly by the adolescents.

Recent migration in the county could have influenced the results of prevalence, especially in the industrial area. While the majority of children with parents with foreign family origin were born in the county, adolescents arrived after preschool age. In general, the prevalence of current wheeze of children and adolescents of North-African family origin is lower than those of South-American origin.

Nevertheless, when restricting the analyses to children born in Spain, the results remained similar (data not shown).

Exposure to environmental tobacco smoke increases the risk of asthma in children and among those with asthma produces more frequent exacerbations and more severe symptoms (Cheraghi and Salvi, 2009). The implementation of smoke-free legislation 
Rovira, E., Cuadras, A., Aguilar, X., Esteban, L., Borras-Santos, A., Zock, J.P., Sunyer, J. Asthma, respiratory symptoms and lung function in children living near a petrochemical site. Environmental Research: 2014, 133, 156-163

in public places in some countries has led to an increase in voluntary restrictions in homes of concerned parents rather than a displacement of smoking to the home (Mackay et al., 2010 and Moore et al., 2012). In Spain, the introduction of smokefree legislation in 2006 has probably contributed to changing habits regarding smoking near children and to a reduction of smoking in private spaces. Our younger study group probably has had most benefit and the changing rates of exposure at preschool age could have contributed to its lowest prevalence of asthma. The prevalence of childhood asthma in Spain has been reported in previous surveys (Aguinaga-Ontoso et al., 1999 and Carvajal-Urueña et al., 2005). Spain is in the worldwide area of medium prevalence, but considerable geographic variations have been described (lower in Mediterranean areas than in the Cantabrian/Atlantic coastal areas). When the data were compared, the prevalence of recent wheezing in the Spanish Mediterranean cities (between 8.3\% and 11.1\%) was similar among children of the present study but not among adolescents (between 7.1\% and 10.3\%). In our study, the prevalence of current rhinitis and rhinoconjunctivitis of the two age groups was in the upper end and the prevalence of eczema was twice as high (Arnedo-Pena et al., 2004 and Suárez-Varela et al., 2008). Those differences in prevalence need to be interpreted with caution because of the time lag existing of about nine years between our study and the ISAAC Spain studies besides; some of the selected Spanish samples were most commonly an urban area and, therefore may not be representative of the total general population.

The response rate achieved was reasonably high and similar in the industrial and in the control areas. However, attending a possible response bias related to the lower response rates in some schools, we repeated the analysis excluding schools with a response rate below $70 \%$. Although the estimates became less stable due to the smaller sample size, overall, no major deviations from the main analysis could be detected (results not shown).

Other sensitivity analyses were performed excluding pupils with asthma ever (75 and 211 pupils 6-7 and 13-14 years-old, respectively), but results did not change (see Fig. 2 in the Supplementary data).

By protocol, the administration of the questionnaire was different for the two age groups. This may have hampered proper comparisons between the two age groups. For instance, adolescents can-not answer with precision about the family history of asthma or about the family education level; otherwise parents can answer in a correct way questions like tobacco consumption at home. Differences in the interpretation of wheezing questions, different parental perception and/or less intensity of exercise at young age may represent an under-reporting by parents and over-reporting by adolescents of exercise-related wheeze (Renzoni et al., 1999).

The present study has other limitations that should be mentioned. First, we considered residential area as an appropriate indirect measure of average exposure to outdoor air pollution rather than school location. Children spend a large proportion of time at school and physical activity increases the ventilation rate and therefore also the dose of inhaled pollutants. A recent study has demonstrated that traffic-related air pollution exposure at school and at home both contribute to the development of asthma (McConnell et al., 2010). As well, school classroom environment might be a significant source of allergen and other indoor exposures, but there is a limited information to evaluate to what extent these exposures contribute to the development of allergic sensitizations and asthma (Salo et al., 2009 and Borràs-Santos et al., 
Rovira, E., Cuadras, A., Aguilar, X., Esteban, L., Borras-Santos, A., Zock, J.P., Sunyer, J. Asthma, respiratory symptoms and lung function in children living near a petrochemical site. Environmental Research: 2014, 133, 156-163

2013). In addition, the design with exposure defined on the basis of geographical area implies that all residents within a particular boundary are equally affected by the hazard of interest without accurate assessment of individual exposure. This may have introduced a bias of the effect estimates towards the null. Furthermore, the present study did not incorporate the proportion of time each child spent indoors and outdoors. Although the role of indoor allergen exposure in the development of allergic sensitization and asthma remains subject to debate, there is strong evidence that indoor allergens play a key role in triggering and exacerbating allergy and asthma symptoms. Information on several potential determinants of indoor air pollution were collected and used in analyses for adjustment. Finally, the choice of residential location can introduce bias in a cross-sectional design that can be difficult to fully detect or control. For instance, families with higher incomes may avoid living near a chemical plant and families with asthmatic children may move away.

\section{CONCLUSIONS}

Our study could not detect a higher prevalence of asthma and allergy symptoms or a reduction of lung function values in children living near the petrochemical area. As observed in other studies, the increase in respiratory hospital admissions and nocturnal cough on children living in the industrial areas could be related with the exposure to petrochemical substances derived from the industry. Specific research on hospitalizations, emergency room visits, asthma and allergy medication use and school absenteeism should be performed. In addition, longitudinal studies with patient panels or chamber studies would be required to understand this increase.

\section{ACKNOWLEDGMENTS}

The authors thank Judith Mariné for their help in the fieldwork, Pilar Hernández in the statistical analysis, Lourdes Arjona with the lung function training, Joan Bellido for their methodological advice and all of the school children and their parents and teachers for their participation.

\section{REFERENCES}

AEQT (Associació Empresarial Química de Tarragona), 2010AEQT (Associació Empresarial Química de Tarragona)Public Report 2010Tarragona, Spain (2010)

Aguinaga-Ontoso et al., 1999I. Aguinaga-Ontoso, A. Arnedo-Pena, J. Bellido, F. GuillénGrima, M.M. Suárez-VarelaThe prevalence of asthma-related symptoms in 13-14-year-old children from 9 Spanish populations. The Spanish Group of the ISAAC Study (International Study of Asthma and Allergies in Childhood)Med. Clin. (Barc.), 112 (1999), pp. 171-175 (in Spanish)

Anandan et al., 2010C. Anandan, U. Nurmatov, O.C. van Schayck, A. Sheikhls the prevalence of asthma declining? Systematic review of epidemiological studiesAllergy, 65 (2010), pp. 152-167 http://dx.doi.org.proxy.library.uu.nl/10.1111/j.1398-9995.2009.02244.x

Arnedo-Pena et al., 2004A. Arnedo-Pena, L. García-Marcos, A. Blanco-Quirós, A. MartínezGimeno, I. Aguinaga-Ontoso, C. González-Díaz, C. Díaz-Vázquez, R. Busquets-Monge, M. Morales-Suárez-Varela, J. Batlles-Garrido, A. López-Silvarrey-Varela, N. García-de AndoinTime trends in prevalence of symptoms of allergic rhinitis in 13-14 year-old schoolchildren in 8 areas of Spain between 1993-1994 and 2001-2002 according to the International Study of Asthma and Allergies in Childhood (ISAAC)Med. Clin. (Barc.), 123 (2004), pp. 490-495 (in Spanish)

Asher et al., 2006M.I. Asher, S. Montefort, B. Björkstén, C.K. Lai, D.P. Strachan, S.K. Weiland, $\mathrm{H}$. WilliamsWorldwide time trends in the prevalence of symptoms of asthma, 
Rovira, E., Cuadras, A., Aguilar, X., Esteban, L., Borras-Santos, A., Zock, J.P., Sunyer, J. Asthma, respiratory symptoms and lung function in children living near a petrochemical site. Environmental Research: 2014, 133, 156-163

allergic rhinoconjunctivitis, and eczema in childhood: ISAAC Phases One and Three repeat multicountry cross-sectional surveysLancet, 368 (2006), pp. 733-743

Bateson and Schwartz, 2008T.F. Bateson, J. SchwartzChildren's response to air pollutantsJ. Toxicol. Environ. Health A, 71 (2008), pp. 238-243

Bell and Ebisu, 2012M.L. Bell, K. EbisuEnvironmental inequality in exposures to airbone particulate matter components in the United StatesEnviron. Health Perspect., 120 (2012), pp. 1699-1704 http://dx.doi.org.proxy.library.uu.nl/10.1289/ehp.1205201

Bolte et al., 2010G. Bolte, G. Tamburlini, M. KohlhuberEnvironmental inequalities among children in Europe-evaluation of scientific evidence and policy implicationsEur. J. Public Health, 20 (2010), pp. 14-20 http://dx.doi.org.proxy.library.uu.nl/10.1093/eurpub/ckp213

Borràs-Santos et al., 2013A. Borràs-Santos, J.H. Jacobs, M. Täubel, U. HaverinenShaughnessy, E.J. Krop, K. Huttunen, M.R. Hirvonen, J. Pekkanen, D.J. Heederik, J.P. Zock, A. HyvärinenDampness and mould in schools and respiratory symptoms in children: the HITEA studyOccup. Environ. Med., 70 (2013), pp. 681-687 http://dx.doi.org.proxy.library.uu.nl/10.1136/oemed-2012-101286

Braman, 2006S.S. BramanThe global burden of asthmaChest, 130 (Suppl. 1) (2006), pp. S4-S12

Brender et al., 2011J.D. Brender, J.A. Maantay, J. ChakrabortyResidential proximity to environmental hazards and adverse health outcomesAm. J. Public Health, 101 (Suppl. 1) (2011), pp. S37-S52 http://dx.doi.org.proxy.library.uu.nl/10.2105/AJPH.2011.300183

Carvajal-Urueña et al., 2005I. Carvajal-Urueña, L. García-Marcos, R. Busquets-Monge, M. Morales-Suárez-Varela, N. García-de Andoin, J. Batlles-Garrido, A. Blanco-Quirós, A. López-Silvarrey, G. García-Hernández, F. Guillén-Grimaj, C. González-Díaz, J. BellidoBlascoGeographic variation in the prevalence of asthma symptoms in Spanish children and adolescents. International Study of Asthma and Allergies in Childhood (ISAAC) Phase 3, SpainArch. Bronconeumol., 41 (2005), pp. 659-666 (in Spanish)

Casan, 1985P. CasanValores espirométricos de referencia para niños y adolescentes sanos (Tesis doctoral)Universidad Autónoma de Barcelona (1985) (in Spanish)

Cheraghi and Salvi, 2009M. Cheraghi, S. SalviEnvironmental tobacco smoke (ETS) and respiratory health in childrenEur. J. Pediatr., 168 (2009), pp. 897-905 http://dx.doi.org.proxy.library.uu.nl/10.1007/s00431-009-0967-3

Currie et al., 2008C. Currie, M. Molcho, W. Boyce, B. Holstein, T. Torsheim, M. RichterResearching health inequalities in adolescents: the development of the Health Behaviour in School-Aged Children (HBSC) family affluence scaleSoc. Sci. Med., 66 (2008), pp. 1429-1436 http://dx.doi.org.proxy.library.uu.nl/10.1016/j.socscimed.2007.11.024

Duijts, 2012L. DuijtsFetal and infant origins of asthmaEur. J. Epidemiol., 27 (2012), pp. 5-14 http://dx.doi.org.proxy.library.uu.nl/10.1007/s10654-012-9657-y

Generalitat de Catalunya, 2010Generalitat de Catalunya. Departament de Territori i Sostenibilitat, 2010. Direcció General de Qualitat Ambiental. Servei de Vigilància i Control de l'Aire. Secció d'Immissions. Balanç de la qualitat de l'aire a Catalunya. Available at http://www20.gencat.cat/portal/site/mediambient/> (accessed 25.04. 14). (in Catalan).

Generalitat de Catalunya, 2010Generalitat de Catalunya. Servei Meteorològic de Catalunya, 2010. Anuari de dades meteorològiques. Available at <

http://www.meteo.cat/servmet/index.html $\quad$ (accessed 25.04.14). (in Catalan).

Götschi et al., 2008T. Götschi, J. Heinrich, J. Sunyer, N. KünzliLong-term effects of ambient air pollution on lung function: a reviewEpidemiology, 19 (2008), pp. 690-701 http://dx.doi.org.proxy.library.uu.nl/10.1097/EDE.0b013e318181650f

Hafkamp-de Groen et al., 2012E. Hafkamp-de Groen, L. van Rossem, J.C. de Jongste, A.D. Mohangoo, H.A. Moll, V.W. Jaddoe, A. Hofman, J.P. Mackenbach, H. RaatThe role of prenatal, perinatal and postnatal factors in the explanation of socioeconomic inequalities in preschool asthma symptoms: the generation R studyJ. Epidemiol. Community Health, 66 (2012), pp. 1017-1024 http://dx.doi.org.proxy.library.uu.nl/10.1136/jech-2011-200333 Hoffmann et al., 2009B. Hoffmann, B. Kolahgar, K. Rauchfuss, G. Eberwein, I. FranzenReuter, M. Kraft, M. Wilhelm, U. Ranft, K.H. JöckelChildhood social position and associations between environmental exposures and health outcomesInt. J. Hyg. Environ. 
Rovira, E., Cuadras, A., Aguilar, X., Esteban, L., Borras-Santos, A., Zock, J.P., Sunyer, J. Asthma, respiratory symptoms and lung function in children living near a petrochemical site. Environmental Research: 2014, 133, 156-163

Health, 212 (2009), pp. 146-156

http://dx.doi.org.proxy.library.uu.nl/10.1016/j.ijheh.2008.04.002

Holguin, 2008F. HolguinTraffic, outdoor air pollution, and asthmalmmunol. Allergy Clin. North Am., 28 (2008), pp. 577-588 http://dx.doi.org.proxy.library.uu.nl/10.1016/j.iac.2008.03.008 Institut d'Estadística de Catalunya, 2010Institut d'Estadística de Catalunya, 2010. Parc de vehicles. Índex de motorització. Available at < http://www.idescat.cat/territ/BasicTerr?TC $=5 \& V 0=1 \& V 1=43148 \& V 3=290 \& V 4=292 \& A L L I N F$ $\mathrm{O}=$ TRUE\&PARENT $=100 \& C T X=\mathrm{B}\rangle$ (accessed 25.04.14). (in Catalan).

IPIECA, 2012IPIECA, 2012. Refinery air emissions management. Guidance document for the oil and gas industry. Available at 〈http://www.ipieca.org/publication/refinery-airemissions-management $\rangle$ (accessed 25.04.14).

International Study of Asthma and Allergies in Childhood Phase Three Study Group, 2009C.K. Lai, R. Beasley, J. Crane, S. Foliaki, J. Shah, S. Weiland, International Study of Asthma and Allergies in Childhood Phase Three Study GroupGlobal variation in the prevalence and severity of asthma symptoms: phase three of the International Study of Asthma and Allergies in Childhood (ISAAC)Thorax, 64 (2009), pp. 476-483 http://dx.doi.org.proxy.library.uu.nl/10.1136/thx.2008.106609

Linares et al., 2010V. Linares, G. Perelló, M. Nadal, J. Gómez-Catalán, J.M. Llobet, J.L. DomingoEnvironmental versus dietary exposure to POPs and metals: a probabilistic assessment of human health risksJ. Environ. Monit., 12 (2010), pp. 681-688 http://dx.doi.org.proxy.library.uu.nl/10.1039/b914962g

Loyo-Berríos et al., 2007N.I. Loyo-Berríos, R. Irizarry, J.G. Hennessey, X.G. Tao, G. MatanoskiAir pollution sources and childhood asthma attacks in Cataño, Puerto RicoAm. J. Epidemiol., 165 (2007), pp. 927-935

Mackay et al., 2010D. Mackay, S. Haw, J.G. Ayres, C. Fischbacher, J.P. PellSmoke-freee legislation and hospitalizations for childhood asthmaN. Engl. J. Med., 363 (2010), pp. 1139-1145 http://dx.doi.org.proxy.library.uu.nl/10.1056/NEJMoa1002861

McConnell et al., 2010R. McConnell, T. Islam, K. Shankardass, M. Jerrett, F. Lurmann, F. Gilliland, J. Gauderman, E. Avol, N. Künzli, L. Yao, J. Peters, K. BerhaneChildhood incident asthma and traffic-related air pollution at home and schoolEnviron. Health Perspect., 118 (2010), pp. 1021-1026

http://dx.doi.org.proxy.library.uu.nl/10.1289/ehp.0901232

Miller and Marty, 2010M.D. Miller, M.A. Martylmpact of environmental chemicals on lung developmentEnviron. Health Perspect., 118 (2010), pp. 1155-1164

http://dx.doi.org.proxy.library.uu.nl/10.1289/ehp.0901856

Miller et al., 2005M.R. Miller, J. Hankinson, V. Brusasco, F. Burgos, R. Casaburi, A. Coates, R. Crapo, P. Enright, C.P. van der Grinten, P. Gustafsson, R. Jensen, D.C. Johnson, N. MacIntyre, R. McKay, D. Navajas, O.F. Pedersen, R. Pellegrino, G. Viegi, J.

WangerStandardisation of spirometryEur. Respir. J., 26 (2005), pp. 319-338

Ministerio de Fomento, 2010Ministerio de Fomento. Mapas provinciales de tráfico, 2010.

Available at 〈http://www.fomento.es〉 (accessed 25.04.14). (in Spanish).

Moore et al., 2012G.F. Moore, D. Currie, G. Gilmore, J.C. Holliday, L. MooreSocioeconomic inequalities in childhood exposure to secondhand smoke before and after smoke-free legislation in three UK countriesJ. Public Health, 34 (2012), pp. 599-608 http://dx.doi.org.proxy.library.uu.nl/10.1093/pubmed/fds025

Moraes et al., 2010A.C. Moraes, E. Ignotti, P.A. Netto, S. Jacobson-Lda, H. Castro, S. Hacon-SdeWheezing in children and adolescents living next to a petrochemical plant in Rio Grande do Norte, BrazilJ. Pediatr. (Rio J.), 86 (2010), pp. 337-344

http://dx.doi.org.proxy.library.uu.nl/10.2223/JPED.2020

Nadal et al., 2011M. Nadal, M. Schuhmacher, J.L. DomingoLong-term environmental monitoring of persistent organic pollutants and metals in a chemical/petrochemical area: human health risksEnviron. Pollut., 159 (2011), pp. 1769-1777 http://dx.doi.org.proxy.library.uu.nl/10.1016/j.envpol.2011.04.007

PRTR-España, 2010PRTR-España, 2010. Spanish Register of Emission and Pollutant Sources. Available at 〈http://www.en.prtr-es.es〉 (accessed 25.04.14) (in Spanish). Ramírez et al., 2011N. Ramírez, A. Cuadras, E. Rovira, R.M. Marcé, F. BorrullRisk assessment related to atmospheric polycyclic aromatic hydrocarbons in gas and particle 
Rovira, E., Cuadras, A., Aguilar, X., Esteban, L., Borras-Santos, A., Zock, J.P., Sunyer, J. Asthma, respiratory symptoms and lung function in children living near a petrochemical site. Environmental Research: 2014, 133, 156-163

phases near industrial sitesEnviron. Health Perspect., 119 (2011), pp. 1100-1106 http://dx.doi.org.proxy.library.uu.nl/10.1289/ehp.1002855

Ramírez et al., 2012N. Ramírez, A. Cuadras, E. Rovira, F. Borrull, R.M. MarcéChronic risk assessment of exposure to volatile organic compounds in the atmosphere near the largest Mediterranean industrial siteEnviron. Int., 39 (2012), pp. 200-209 http://dx.doi.org.proxy.library.uu.nl/10.1016/j.envint.2011.11.002

Renzoni et al., 1999E. Renzoni, F. Forastiere, A. Biggeri, G. Viegi, L. Bisanti, E. Chellini, G. Ciccone, G. Corbo, C. Galassi, F. Rusconi, P. SestiniDifferences in parental- and selfreport of asthma, rhinitis and eczema among Italian adolescents. SIDRIA collaborative group. Studi Italiani sui Disordini Respiratori dell'Infanzia e l'AmbienteEur. Respir. J., 14 (1999), pp. 597-604

Rovira et al., 2010E. Rovira, A. Cuadras, P. Gaig, V. Gázquez, G. Dalmau, S. Gómez-Ollés, M.J. CruzSoybean hull unloading in Tarragona (Spain) and asthma outbreak riskGac. Sanit., 24 (2010), pp. 109-114 http://dx.doi.org.proxy.library.uu.nl/10.1016/j.gaceta.2009.09.018

Rusconi et al., 2011F. Rusconi, D. Catelan, G. Accetta, M. Peluso, R. Pistelli, F. Barbone, E. Di Felice, A. Munnia, P. Murgia, L. Paladini, A. Serci, A. BiggeriAsthma symptoms, lung function, and markers of oxidative stress and inflammation in children exposed to oil refinery pollutionJ. Asthma, 48 (2011), pp. 84-90 http://dx.doi.org.proxy.library.uu.nl/10.3109/02770903.2010.538106

Salo et al., 2009P.M. Salo, M.L. Sever, D.C. ZeldinIndoor allergens in school and day care environmentsJ. Allergy Clin. Immunol., 124 (2009), pp. 185-192 http://dx.doi.org.proxy.library.uu.nl/10.1016/j.jaci.2009.05.012

Smargiassi et al., 2009A. Smargiassi, T. Kosatsky, J. Hicks, C. Plante, B. Armstrong, P.J. Villeneuve, S. GoudreauRisk of asthmatic episodes in children exposed to sulfur dioxide stack emissions from a refinery point source in Montreal, CanadaEnviron. Health Perspect., 117 (2009), pp. 653-659 http://dx.doi.org.proxy.library.uu.nl/10.1289/ehp.0800010

Suárez-Varela et al., 2008M.M. Suárez-Varela, L. García-Marcos Alvarez, M.D. Kogan, A.L. González, A.M. Gimeno, I. Aguinaga Ontoso, C.G. Díaz, A.A. Pena, B.D. Aurrecoechea, R.M. Monge, A.B. Quiros, J.B. Garrido, I.M. Canflanca, A.L. VarelaClimate and prevalence of atopic eczema in 6- to 7-year-old school children in Spain. ISAAC Phase IIIInt. J. Biometeorol., 52 (2008), pp. 833-840 http://dx.doi.org.proxy.library.uu.nl/10.1007/s00484008-0177-0

Tzivian, 2011L. TzivianOutdoor air pollution and asthma in childrenJ. Asthma, 48 (2011), pp. 470-481 http://dx.doi.org.proxy.library.uu.nl/10.3109/02770903.2011.570407

Ware et al., 1993J.H. Ware, J.D. Spengler, L.M. Neas, J.M. Samet, G.R. Wagner, D. Coultas, H. Ozkaynak, M. SchwabRespiratory and irritant health effects of ambient volatile organic compounds. The Kanawha County Health StudyAm. J. Epidemiol., 137 (1993), pp. $1287-1301$

White et al., 2009N. White, J. teWaterNaude, A. van der Walt, G. Ravenscroft, W. Roberts, R. EhrlichMeteorologically estimated exposure but not distance predicts asthma symptoms in schoolchildren in the environs of a petrochemical refinery: a cross-sectional studyEnviron. Health, 8 (2009), p. 45 http://dx.doi.org.proxy.library.uu.nl/10.1186/1476069X-8-45

Whitworth et al., 2008K.W. Whitworth, E. Symanski, A.L. CokerChildhood lymphohematopoietic cancer incidence and hazardous air pollutants in southeast Texas, 1995-2004Environ. Health Perspect., 116 (2008), pp. 1576-1580 http://dx.doi.org.proxy.library.uu.nl/10.1289/ehp.11593

Wichmann et al., 2009F.A. Wichmann, A. Müller, L.E. Busi, N. Cianni, L. Massolo, U. Schlink, A. Porta, P.D. Slylncreased asthma and respiratory symptoms in children exposed to petrochemical pollutionJ. Allergy Clin. Immunol., 123 (2009), pp. 632-638

http://dx.doi.org.proxy.library.uu.nl/10.1016/j.jaci.2008.09.052

Yang et al., 1998C.Y. Yang, J.D. Wang, C.C. Chan, J.S. Hwang, P.C. ChenRespiratory symptoms of primary school children living in a petrochemical polluted area in TaiwanPediatr. Pulmonol., 25 (1998), pp. 299-303

Yang et al., 2004C.Y. Yang, C.C. Chang, H.Y. Chuang, C.K. Ho, T.N. Wu, P.Y. Changlncreased risk of preterm delivery among people living near the three oil refineries in 
Rovira, E., Cuadras, A., Aguilar, X., Esteban, L., Borras-Santos, A., Zock, J.P., Sunyer, J.

Asthma, respiratory symptoms and lung function in children living near a petrochemical site.

Environmental Research: 2014, 133, 156-163

TaiwanEnviron. Int., 30 (2004), pp. 337-342

http://dx.doi.org.proxy.library.uu.nl/10.1016/S0160-4120(03)00180-6

Tables and figures

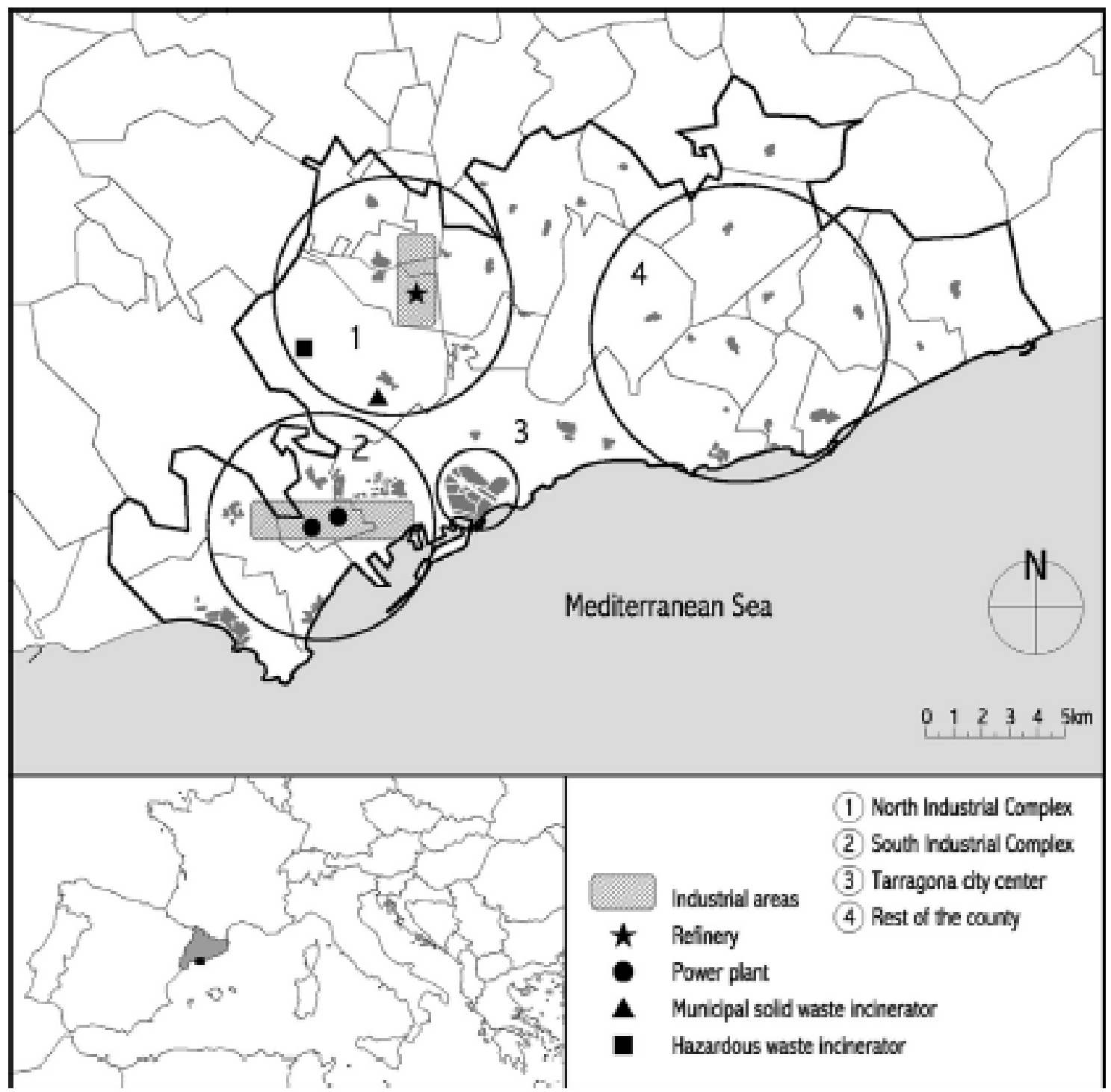

Fig 1. Map of the study area. 
Rovira, E., Cuadras, A., Aguilar, X., Esteban, L., Borras-Santos, A., Zock, J.P., Sunyer, J.

Asthma, respiratory symptoms and lung function in children living near a petrochemical site.

Environmental Research: 2014, 133, 156-163

[TABLE 1]

Demographic characteristics of study participants by age group and geographic area.

\begin{tabular}{|c|c|c|c|c|c|c|}
\hline \multicolumn{2}{|c|}{ Characteristic } & $\begin{array}{c}\text { North } \\
\text { industrial } \\
\text { complex } \\
\end{array}$ & \begin{tabular}{|c|}
$\begin{array}{c}\text { South } \\
\text { industrial } \\
\text { complex }\end{array}$ \\
\end{tabular} & $\begin{array}{l}\text { Tarragona } \\
\text { city center }\end{array}$ & $\begin{array}{c}\text { Rest of } \\
\text { the } \\
\text { county }\end{array}$ & Total \\
\hline \multicolumn{7}{|l|}{ 6-7 years } \\
\hline \multicolumn{2}{|c|}{ Participation (\%) } & 58.5 & 54.4 & 64.9 & 56.7 & 58.9 \\
\hline \multicolumn{2}{|c|}{ Valid questionnaires } & 304 & 401 & 340 & 466 & 1511 \\
\hline \multicolumn{2}{|c|}{ Age, years (mean, SD) } & $6.9(0.3)$ & $6.8(0.3)$ & $6.8(0.3)$ & \begin{tabular}{|l}
6.8 \\
$(0.3)$ \\
\end{tabular} & \begin{tabular}{|l|}
6.8 \\
$(0.3)$ \\
\end{tabular} \\
\hline \multicolumn{2}{|c|}{ Sex, male (\%) } & 56.6 & 52.1 & 47.4 & 53.4 & 52.3 \\
\hline \multicolumn{2}{|c|}{$\begin{array}{l}\text { Length of residence in } \\
\text { the town, years (mean, } \\
\text { SD) }\end{array}$} & $5.6(1.7)$ & $5.6(1.5)$ & $6.0(1.2)^{\square \square}$ & $\begin{array}{l}5.6 \\
(1.7)\end{array}$ & $\begin{array}{l}5.7 \\
(1.5)\end{array}$ \\
\hline \multicolumn{2}{|c|}{$\begin{array}{l}\text { Family origin, both } \\
\text { parents non-Spanish } \\
(\%)\end{array}$} & 11.0 & $18.3^{\square \square}$ & 11.3 & $\mid 0.5$ & $\mid 12.9$ \\
\hline \multirow[t]{3}{*}{$\begin{array}{l}\text { Family } \\
\text { Affluence } \\
\text { Scale (\%) } \\
\end{array}$} & Low & $22.3^{\square}$ & $27.3^{\square \square}$ & $18.4^{\square}$ & $\mid 16.0$ & 20.8 \\
\hline & Medium & 40.7 & 45.5 & 46.9 & 39.7 & 43.0 \\
\hline & High & 37.0 & 27.3 & 34.7 & 44.3 & 36.1 \\
\hline \multicolumn{2}{|c|}{$\begin{array}{l}\text { Family education } \\
\text { level, low (\%) }\end{array}$} & $\mid 21.3^{\square \square}$ & $29.4^{\square \square}$ & $5.4^{\square \square}$ & 15.6 & 18.0 \\
\hline \multicolumn{2}{|c|}{$\begin{array}{l}\text { Environmental } \\
\text { tobacco exposure at } \\
\text { home (\%) }\end{array}$} & 12.0 & 13.9 & 13.3 & 14.9 & $\mid 13.7$ \\
\hline \multicolumn{2}{|c|}{$\begin{array}{l}\text { Family history of } \\
\text { asthma (\%) }\end{array}$} & 14.0 & 15.5 & 10.5 & 13.0 & 13.3 \\
\hline \multicolumn{2}{|c|}{$\begin{array}{l}\text { Hospitalizations by } \\
\text { respiratory disease, } \\
\text { last year (\%) }\end{array}$} & $19.3^{\square \square}$ & 13.8 & 13.6 & 12.1 & $\mid 14.3$ \\
\hline \multicolumn{7}{|c|}{ 13-14 years } \\
\hline \multicolumn{2}{|c|}{ Participation (\%) } & 75.6 & 73.0 & 82.6 & 75.3 & 77.1 \\
\hline \multicolumn{2}{|c|}{ Valid questionnaires } & 269 & 427 & 405 & 493 & 1,594 \\
\hline \multicolumn{2}{|c|}{ Age, years (mean, SD) } & $14.0(0.4)$ & $14.0(0.4)$ & $13.9(0.4)$ & $\left(\begin{array}{l}14.0 \\
(0.4)\end{array}\right)$ & $\left(\begin{array}{l}14.0 \\
(0.4)\end{array}\right)$ \\
\hline \multicolumn{2}{|c|}{ Sex, male (\%) } & 54.6 & 48.9 & $43.2^{\square \square}$ & 53.5 & 49.8 \\
\hline \multicolumn{2}{|c|}{$\begin{array}{l}\text { Length of residence in } \\
\text { the town, years (mean, }\end{array}$} & 10.6 (4.2) & $10.4(4.3)$ & $11.7(3.4)^{\square \square}$ & $\left(\begin{array}{l}10.1 \\
(4.4)\end{array}\right)$ & $\left(\begin{array}{l}10.7 \\
(4.1)\end{array}\right)$ \\
\hline
\end{tabular}


Rovira, E., Cuadras, A., Aguilar, X., Esteban, L., Borras-Santos, A., Zock, J.P., Sunyer, J.

Asthma, respiratory symptoms and lung function in children living near a petrochemical site.

Environmental Research: 2014, 133, 156-163

\begin{tabular}{|c|c|c|c|c|c|c|}
\hline \multicolumn{2}{|c|}{ Characteristic } & $\begin{array}{c}\text { North } \\
\text { industrial } \\
\text { complex }\end{array}$ & \begin{tabular}{|c|} 
South \\
industrial \\
complex
\end{tabular} & $\begin{array}{l}\text { Tarragona } \\
\text { city center }\end{array}$ & $\begin{array}{c}\text { Rest of } \\
\text { the } \\
\text { county }\end{array}$ & Total \\
\hline \multicolumn{7}{|l|}{ SD) } \\
\hline \multicolumn{2}{|c|}{$\begin{array}{l}\text { Family origin, both } \\
\text { parents non-Spanish } \\
(\%)\end{array}$} & $\mid 10.1$ & $26.1^{\square \square}$ & 12.6 & 14.5 & 16.4 \\
\hline \multirow[t]{3}{*}{\begin{tabular}{|l} 
Family \\
Affluence \\
Scale (\%) \\
\end{tabular}} & Low & $10.8^{\square}$ & $14.2^{\square \square}$ & $6.9^{\square \square}$ & |5.5 & 9.1 \\
\hline & Medium & 27.5 & 36.6 & 37.2 & 27.8 & 32.5 \\
\hline & High & 61.7 & 49.2 & 55.8 & 66.7 & 58.4 \\
\hline \multicolumn{2}{|c|}{$\begin{array}{l}\begin{array}{l}\text { Family education } \\
\text { level, low (\%) }\end{array} \\
\end{array}$} & $13.7^{\square \square}$ & $16.3^{\square \square}$ & 4.4 & || 7.0 & 9.6 \\
\hline \multicolumn{2}{|c|}{$\begin{array}{l}\text { Environmental } \\
\text { tobacco exposure at } \\
\text { home }(\%) \\
\end{array}$} & 35.4 & 38.2 & 30.9 & 35.3 & 35.0 \\
\hline \multicolumn{2}{|c|}{$\begin{array}{l}\text { Family history of } \\
\text { asthma (\%) }\end{array}$} & |12.1 & 11.3 & 9.4 & 10.3 & $\mid 10.6$ \\
\hline \multicolumn{2}{|c|}{$\begin{array}{l}\text { Tobacco consumption, } \\
\text { last month (\%) }\end{array}$} & $\mid 6.7^{\square \square}$ & $8.5^{\square}$ & $\mid 8.7^{\square}$ & $\mid 13.2$ & 9.7 \\
\hline
\end{tabular}

Chi-square for categorical variables and Mann-Whitney test for continuous variables.

Significantly different from control area Rest of the county $(p<0.05)$.

Significantly different from control area Rest of the county $(p<0.01)$. 
Rovira, E., Cuadras, A., Aguilar, X., Esteban, L., Borras-Santos, A., Zock, J.P., Sunyer, J.

Asthma, respiratory symptoms and lung function in children living near a petrochemical site.

Environmental Research: 2014, 133, 156-163

[TABLE 2]

Prevalence of symptoms by age group and geographic area.

\begin{tabular}{|c|c|c|c|c|c|}
\hline $\begin{array}{c}\text { Symptoms, \% (95\% } \\
\text { CI) }\end{array}$ & \begin{tabular}{|c|} 
North \\
industrial \\
complex \\
\end{tabular} & $\begin{array}{c}\text { South } \\
\text { industrial } \\
\text { complex } \\
\end{array}$ & $\begin{array}{l}\text { Tarragona } \\
\text { city center }\end{array}$ & \begin{tabular}{|c|} 
Rest of \\
the \\
county
\end{tabular} & Total \\
\hline \multicolumn{6}{|l|}{ 6-7 years } \\
\hline Wheezing ever & $\mid \begin{array}{l}39.8(34.3- \\
45.3)\end{array}$ & $\mid \begin{array}{l}34.9(30.2- \\
39.6)\end{array}$ & $\begin{array}{l}33.5(28.5- \\
38.5)\end{array}$ & \begin{tabular}{|l}
38.6 \\
$(34.2-$ \\
$43.0)$ \\
\end{tabular} & \begin{tabular}{|l|}
36.7 \\
$(34.3-$ \\
$39.1)$ \\
\end{tabular} \\
\hline $\begin{array}{l}\text { Wheezing in the past } \\
\text { year }\end{array}$ & $\mid \begin{array}{l}9.5(6.2- \\
12.8)\end{array}$ & $\begin{array}{l}9.5(6.6- \\
12.4)\end{array}$ & $\begin{array}{l}8.2(5.3- \\
11.1)\end{array}$ & $\begin{array}{l}10.5 \\
(7.7- \\
13.3) \\
\end{array}$ & $\begin{array}{l}9.5 \\
(8.0- \\
11.0) \\
\end{array}$ \\
\hline Severe wheezing & $\begin{array}{l}2.0(0.4- \\
3.6)\end{array}$ & $\begin{array}{l}2.7(1.1- \\
4.3)\end{array}$ & $\begin{array}{l}2.1(0.6- \\
3.6)\end{array}$ & $\begin{array}{l}1.7 \\
(0.5- \\
2.9) \\
\end{array}$ & $\begin{array}{l}2.1 \\
(1.4- \\
2.8) \\
\end{array}$ \\
\hline Asthma ever & $\begin{array}{l}4.6(2.2- \\
7.0)\end{array}$ & $\begin{array}{l}4.5(2.5- \\
6.5)\end{array}$ & $\begin{array}{l}5.3(2.9- \\
7.7)\end{array}$ & \begin{tabular}{|l|}
5.4 \\
$(3.3-$ \\
$7.5)$ \\
\end{tabular} & \begin{tabular}{|l}
5.0 \\
$(3.9-$ \\
$6.1)$ \\
\end{tabular} \\
\hline $\begin{array}{l}\text { Wheezing with } \\
\text { exercise in the past } \\
\text { year }\end{array}$ & $\begin{array}{l}4.9(2.5- \\
7.3)\end{array}$ & $\begin{array}{l}3.0(1.3- \\
4.7)\end{array}$ & $\begin{array}{l}2.1(0.6- \\
3.6)\end{array}$ & \begin{tabular}{|l|}
3.2 \\
$(1.6-$ \\
$4.8)$ \\
\end{tabular} & \begin{tabular}{|l}
3.2 \\
$(2.3-$ \\
$4.1)$ \\
\end{tabular} \\
\hline $\begin{array}{l}\text { Nocturnal dry cough } \\
\text { in the past year }\end{array}$ & $\mid \begin{array}{l}23.4(18.6- \\
28.2)\end{array}$ & $\mid \begin{array}{l}21.4(17.4- \\
25.4)\end{array}$ & $\begin{array}{l}18.2(14.1- \\
22.3)\end{array}$ & \begin{tabular}{|l}
18.2 \\
$(14.7-$ \\
$21.7)$ \\
\end{tabular} & \begin{tabular}{|l|}
20.1 \\
$(18.1-$ \\
$22.1)$ \\
\end{tabular} \\
\hline $\begin{array}{l}\text { Rhinitis in the past } \\
\text { year }\end{array}$ & $\mid \begin{array}{l}22.0(17.3- \\
26.7)\end{array}$ & $\mid \begin{array}{l}19.0(15.2- \\
22.8)\end{array}$ & $\begin{array}{l}16.5(12.6- \\
20.4)\end{array}$ & $\begin{array}{l}17.4 \\
(14.0- \\
20.8) \\
\end{array}$ & \begin{tabular}{|l|}
18.5 \\
$(16.5-$ \\
$20.5)$ \\
\end{tabular} \\
\hline $\begin{array}{l}\text { Rhinoconjunctivitis } \\
\text { in the past year }\end{array}$ & $\begin{array}{l}9.2(6.0- \\
12.4)\end{array}$ & $\begin{array}{l}9.0(6.2- \\
11.8)\end{array}$ & $\begin{array}{l}4.7(2.5- \\
6.9)\end{array}$ & \begin{tabular}{|l}
6.4 \\
$(4.2-$ \\
$8.6)$ \\
\end{tabular} & \begin{tabular}{|l}
7.3 \\
$(6.0-$ \\
$8.6)$ \\
\end{tabular} \\
\hline Nasal allergy ever & $\begin{array}{l}6.9(4.1- \\
9.7)\end{array}$ & $\begin{array}{l}7.7(5.1- \\
10.3)\end{array}$ & $\begin{array}{l}5.0(2.7- \\
7.3)\end{array}$ & $\begin{array}{l}5.4 \\
(3.3- \\
7.5) \\
\end{array}$ & $\begin{array}{l}6.2 \\
(5.0- \\
7.4) \\
\end{array}$ \\
\hline $\begin{array}{l}\text { Eczema in the past } \\
\text { year }\end{array}$ & \begin{tabular}{|l|}
$14.1(10.2-$ \\
$18.0)$
\end{tabular} & $\begin{array}{l}8.2(5.5- \\
10.9)\end{array}$ & $\begin{array}{l}11.5(8.1- \\
14.9)\end{array}$ & $\begin{array}{l}10.1 \\
(7.4- \\
12.8) \\
\end{array}$ & $\begin{array}{l}10.7 \\
(9.1- \\
12.3) \\
\end{array}$ \\
\hline Atopic dermatitis & $\begin{array}{l}44.7(39.1- \\
50.3)\end{array}$ & $\mid \begin{array}{l}36.9(32.2- \\
41.6)\end{array}$ & $\begin{array}{l}47.4(42.1- \\
52.7)\end{array}$ & \begin{tabular}{|l}
44.2 \\
$(39.7-$ \\
$48.7)$ \\
\end{tabular} & \begin{tabular}{|l}
43.1 \\
$(40.6-$ \\
$45.6)$ \\
\end{tabular} \\
\hline \multicolumn{6}{|l|}{ 13-14 years } \\
\hline Wheezing ever & $\begin{array}{l}27.1(21.8- \\
32.4)\end{array}$ & $\begin{array}{l}32.6(28.2- \\
37.0)\end{array}$ & $\begin{array}{l}23.5(19.4- \\
27.6)^{\square}\end{array}$ & \begin{tabular}{|l}
29.8 \\
$(25.8-$ \\
$33.8)$ \\
\end{tabular} & \begin{tabular}{|l}
28.5 \\
$(26.3-$ \\
$30.7)$
\end{tabular} \\
\hline
\end{tabular}


Rovira, E., Cuadras, A., Aguilar, X., Esteban, L., Borras-Santos, A., Zock, J.P., Sunyer, J.

Asthma, respiratory symptoms and lung function in children living near a petrochemical site.
Environmental Research: 2014, 133, 156-163

\begin{tabular}{|c|c|c|c|c|c|}
\hline $\begin{array}{c}\text { Symptoms, \% (95\% } \\
\text { CI) }\end{array}$ & $\begin{array}{c}\text { North } \\
\text { industrial } \\
\text { complex }\end{array}$ & $\begin{array}{c}\text { South } \\
\text { industrial } \\
\text { complex }\end{array}$ & $\begin{array}{l}\text { Tarragona } \\
\text { city center }\end{array}$ & \begin{tabular}{|c|}
$\begin{array}{c}\text { Rest of } \\
\text { the } \\
\text { county }\end{array}$ \\
\end{tabular} & Total \\
\hline $\begin{array}{l}\text { Wheezing in the past } \\
\text { year }\end{array}$ & $\begin{array}{l}14.1(9.9- \\
18.3)\end{array}$ & $\begin{array}{l}18.0(14.4- \\
21.6)\end{array}$ & $\begin{array}{l}12.8(9.5- \\
16.1)^{\square}\end{array}$ & \begin{tabular}{|l}
19.3 \\
$(15.8-$ \\
$22.8)$ \\
\end{tabular} & $\begin{array}{l}16.4 \\
(14.6- \\
18.2) \\
\end{array}$ \\
\hline Severe wheezing & $\begin{array}{l}5.9(3.1- \\
8.7)\end{array}$ & $\begin{array}{l}8.4(5.8- \\
11.0)\end{array}$ & $\begin{array}{l}4.9(2.8- \\
7.0)\end{array}$ & $\begin{array}{l}7.5 \\
(5.2- \\
9.8) \\
\end{array}$ & \begin{tabular}{|l}
6.8 \\
$(5.6-$ \\
$8.0)$ \\
\end{tabular} \\
\hline Asthma ever & $\begin{array}{l}12.3(8.4- \\
16.2)\end{array}$ & $\begin{array}{l}13.6(10.3- \\
16.9)\end{array}$ & $\begin{array}{l}15.1(11.6- \\
18.6)\end{array}$ & $\begin{array}{l}14.0 \\
(10.9- \\
17.1) \\
\end{array}$ & $\begin{array}{l}13.9 \\
(12.2- \\
15.6) \\
\end{array}$ \\
\hline $\begin{array}{l}\text { Wheezing wi } \\
\text { exercise in th } \\
\text { year }\end{array}$ & $\begin{array}{l}18.2(13.6- \\
22.8)\end{array}$ & $\mid \begin{array}{l}22.0(18.1- \\
25.9)\end{array}$ & $\begin{array}{l}17.3(13.6- \\
21.0)\end{array}$ & $\begin{array}{l}19.5 \\
(16.0- \\
23.0) \\
\end{array}$ & $\begin{array}{l}19.4 \\
(17.5- \\
21.3) \\
\end{array}$ \\
\hline $\begin{array}{l}\text { Nocturnal dry cough } \\
\text { in the past year }\end{array}$ & $\begin{array}{l}43.9(38.0- \\
49.8)\end{array}$ & \begin{tabular}{|l}
$39.3(34.7-$ \\
$43.9)$
\end{tabular} & $\begin{array}{l}34.8(30.2- \\
39.4)\end{array}$ & \begin{tabular}{|l}
34.3 \\
$(30.1-$ \\
$38.5)$ \\
\end{tabular} & \begin{tabular}{|l|}
37.4 \\
$(35.0-$ \\
$39.8)$ \\
\end{tabular} \\
\hline $\begin{array}{l}\text { Rhinitis in the past } \\
\text { year }\end{array}$ & $\begin{array}{l}35.7(30.0- \\
41.4)\end{array}$ & $\mid \begin{array}{l}33.5(29.0- \\
38.0)\end{array}$ & $\begin{array}{l}39.5(34.7- \\
44.3)\end{array}$ & $\begin{array}{l}36.9 \\
(32.6- \\
41.2) \\
\end{array}$ & $\begin{array}{l}36.4 \\
(34.0- \\
38.8) \\
\end{array}$ \\
\hline $\begin{array}{l}\text { Rhinoconjunctivitis } \\
\text { in the past year }\end{array}$ & $\begin{array}{l}16.4(12.0- \\
20.8)\end{array}$ & $\mid \begin{array}{l}18.0(14.4- \\
21.6)\end{array}$ & $\begin{array}{l}19.5(15.6- \\
23.4)\end{array}$ & $\begin{array}{l}18.3 \\
(14.9- \\
21.7) \\
\end{array}$ & $\begin{array}{l}18.2 \\
(16.3- \\
20.1) \\
\end{array}$ \\
\hline Nasal allergy ever & $\begin{array}{l}15.2(10.9 \\
19.5)\end{array}$ & \begin{tabular}{|l}
$15.5(12.1-$ \\
$18.9)$
\end{tabular} & $\begin{array}{l}11.6(8.5- \\
14.7)\end{array}$ & \begin{tabular}{|l}
15.6 \\
$(12.4-$ \\
$18.8)$ \\
\end{tabular} & $\begin{array}{l}14.5 \\
(12.8- \\
16.2) \\
\end{array}$ \\
\hline $\begin{array}{l}\text { Eczema in the past } \\
\text { year }\end{array}$ & $\begin{array}{l}10.0(6.4- \\
13.6)\end{array}$ & $\begin{array}{l}10.1(7.2- \\
13.0)\end{array}$ & $\begin{array}{l}10.9(7.9- \\
13.9)\end{array}$ & $\begin{array}{l}10.1 \\
(7.4- \\
12.8) \\
\end{array}$ & $\begin{array}{l}10.3 \\
(8.8- \\
11.8) \\
\end{array}$ \\
\hline Atopic dermatitis & $\begin{array}{l}18.2(13.6- \\
22.8)\end{array}$ & $\mid \begin{array}{l}17.6(14.0- \\
21.2)\end{array}$ & $\begin{array}{l}19.0(15.2- \\
22.8)\end{array}$ & \begin{tabular}{|l}
16.4 \\
$(13.1-$ \\
$19.7)$ \\
\end{tabular} & $\begin{array}{l}17.7 \\
(15.8- \\
19.6) \\
\end{array}$ \\
\hline
\end{tabular}

Chi-square.

Significantly different from control area Rest of the county $(p<0.05)$.

Significantly different from control area Rest of the county $(p<0.01)$. 
Rovira, E., Cuadras, A., Aguilar, X., Esteban, L., Borras-Santos, A., Zock, J.P., Sunyer, J. Asthma, respiratory symptoms and lung function in children living near a petrochemical site. Environmental Research: 2014, 133, 156-163

6-7years

Wheezing ever

Wheezing in the past year

Severe wheezing

Asthma ever

Wheezingwith exercise in the past year

Nocturnal dry cough in the past year

Rhinitis in the past year

Rhinoconjunctivitis in the pastyear

Nasal allergy ever

Eczema in the past year

Atopic dermatitis

Respiratoryhospitalizations in the past year

13-14 years

Wheezing ever

Wheezing in the past year

Severe wheezing

Asthma ever

Wheezing with exercise in the past year

Nocturnal dry cough in the past year

Rhinitis in the past year

Rhinoconjunctivitis in the pastyear

Nasal allergy ever

Eczerna in the pastyear

Atopic dermatitis
NC
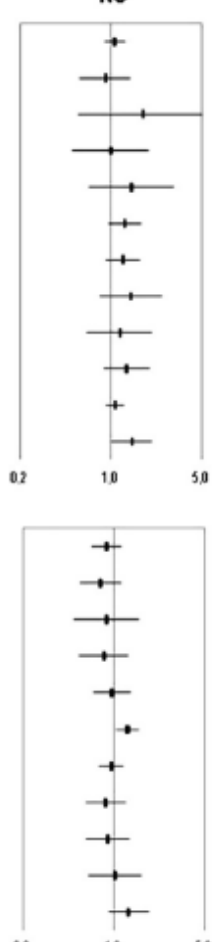

sc
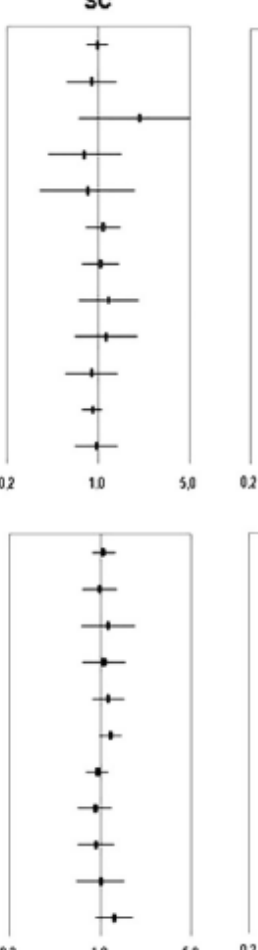

TC
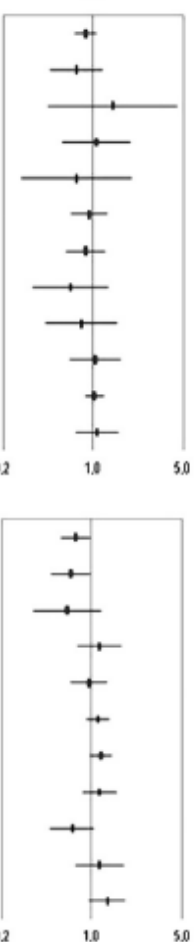

Fig. 2. Adjusted prevalence ratios (95\% confidence interval) for asthma and allergy symptoms (written questionnaire) by age group and geographic area. Adjusted for gender, length of residence in the town, parental nationality, parental history of asthma, family affluence and passive and active smoking (13-14 years old group). 
Rovira, E., Cuadras, A., Aguilar, X., Esteban, L., Borras-Santos, A., Zock, J.P., Sunyer, J.

Asthma, respiratory symptoms and lung function in children living near a petrochemical site.

Environmental Research: 2014, 133, 156-163

\section{[TABLE 3]}

Characteristics of adolescents and lung function values by geographic area.

\begin{tabular}{|c|c|c|c|c|c|}
\hline Characteristic & $\begin{array}{c}\text { North } \\
\text { industrial } \\
\text { complex }\end{array}$ & $\begin{array}{c}\text { South } \\
\text { industrial } \\
\text { complex }\end{array}$ & $\begin{array}{l}\text { Tarragona } \\
\text { city center }\end{array}$ & $\begin{array}{c}\text { Rest of } \\
\text { the } \\
\text { county }\end{array}$ & Total \\
\hline $\begin{array}{l}\text { Number } \\
\text { recruited }\end{array}$ & 92 & 174 & 142 & 117 & 525 \\
\hline Male (\%) & 52.2 & 49.4 & 44.4 & 53.0 & 49.3 \\
\hline $\begin{array}{l}\text { Height }(\mathrm{cm}, \\
\text { mean, SD) }\end{array}$ & $163.8(7.7)$ & $162.0(6.9)$ & $163.1(6.5)$ & $\begin{array}{l}163.0 \\
(8.3) \\
\end{array}$ & $\begin{array}{l}162.8 \\
(7.3) \\
\end{array}$ \\
\hline $\begin{array}{l}\text { Weight (kg, } \\
\text { mean, SD) }\end{array}$ & \begin{tabular}{|l|}
59.4 \\
$(10.2)$ \\
\end{tabular} & 57.4 (12.8) & $57.4(10.6)$ & \begin{tabular}{|l}
55.3 \\
$(10.8)$ \\
\end{tabular} & \begin{tabular}{|l|}
57.3 \\
$(11.4)$ \\
\end{tabular} \\
\hline $\begin{array}{l}\text { FVC (\% } \\
\text { predicted, SD) }\end{array}$ & $91.1(10.6)$ & 92.9 (10.9) & $91.1(10.0)$ & \begin{tabular}{|l}
92.0 \\
$(10.7)$ \\
\end{tabular} & $\begin{array}{l}91.9 \\
(10.6) \\
\end{array}$ \\
\hline $\begin{array}{l}\mathrm{FEV}_{1}(\% \\
\text { predicted, SD) } \\
\end{array}$ & 94.0 (11.7) & 96.4 (11.1) & $94.3(11.0)$ & $\begin{array}{l}95.7 \\
(11.4) \\
\end{array}$ & \begin{tabular}{|l|}
95.3 \\
$(11.3)$ \\
\end{tabular} \\
\hline $\begin{array}{l}\text { PEF (\% } \\
\text { predicted, SD) }\end{array}$ & 103.2 (15.3) & $103.5(15.0)$ & $102.8(14.2)$ & $\begin{array}{l}104.5 \\
(13.9)\end{array}$ & $\begin{array}{l}103.5 \\
(14.6)\end{array}$ \\
\hline $\begin{array}{l}\mathrm{FEV}_{1} / \mathrm{FVC} \text { ratio } \\
(\%, \mathrm{SD})\end{array}$ & 87.2 (6.3) & $88.0(5.7)$ & $88.0(6.3)$ & $\begin{array}{l}88.3 \\
(6.5)\end{array}$ & $\begin{array}{l}87.9 \\
(6.1)\end{array}$ \\
\hline
\end{tabular}

Abbreviations: FVC, forced vital capacity; $\mathrm{FEV}_{1}$, forced expiratory volume within 1 s; PEF, peak expiratory flow; SD, standard deviation.

$T$-test (for normally distributed) or Mann-Whitney test (for non-normal distribution).

Significantly different from control area Rest of the county $(p<0.01)$. 
Rovira, E., Cuadras, A., Aguilar, X., Esteban, L., Borras-Santos, A., Zock, J.P., Sunyer, J.

Asthma, respiratory symptoms and lung function in children living near a petrochemical site.

Environmental Research: 2014, 133, 156-163

\section{[TABLE 4]}

Differences in lung function values between industrial and urban areas compared to control area, adjusted for confounding variables.

\begin{tabular}{|c|c|c|c|c|c|c|}
\hline & \multicolumn{2}{|c|}{$\begin{array}{l}\text { North industrial } \\
\text { complex }\end{array}$} & \multicolumn{2}{|c|}{$\begin{array}{c}\text { South industrial } \\
\text { complex }\end{array}$} & \multicolumn{2}{|c|}{$\begin{array}{l}\text { Tarragona city } \\
\text { center }\end{array}$} \\
\hline & B & $95 \%$ CI & B & $95 \% \mathrm{CI}$ & B & $95 \% \mathrm{CI}$ \\
\hline $\mathrm{FVC}(\mathrm{ml} / \mathrm{s})$ & -11 & -59 to 36 & 1 & -62 to 64 & -12 & \begin{tabular}{|l}
-134 to \\
111
\end{tabular} \\
\hline $\mathrm{FEV}_{1}(\mathrm{ml} / \mathrm{s})$ & -9 & -50 to 33 & 10 & -42 to 63 & -54 & -164 to 55 \\
\hline PEF (ml/s) & -75 & -176 to 26 & -87 & -214 to 41 & -222 & -485 to 42 \\
\hline $\begin{array}{l}\mathrm{FEV}_{1} / \mathrm{FVC} \\
\text { ratio (\%) }\end{array}$ & -0.050 & \begin{tabular}{|l|}
-0.645 to \\
0.544 \\
\end{tabular} & 0.106 & \begin{tabular}{|l|}
-0.617 to \\
0.829
\end{tabular} & -1.389 & $\begin{array}{l}-3.091 \text { to } \\
0.313\end{array}$ \\
\hline
\end{tabular}

Abbreviations: B, regression coefficient; CI, confidence interval; FVC, forced vital capacity; $\mathrm{FEV}_{1}$, forced expiratory volume within $1 \mathrm{~s}$; PEF, peak expiratory flow. Adjusted for height, height square, weight, gender, length of residence in the town, parental nationality, parental history of asthma, family affluence and passive and active smoking. 